\title{
Gamma background measurements in the Laboratoire Souterrain de Modane
}

\author{
Dariusz Malczewski $\cdot$ Jan Kisiel $\cdot$ Jerzy Dorda
}

Received: 5 October 2011 / Published online: 1 November 2011

(C) The Author(s) 2011. This article is published with open access at Springerlink.com

\begin{abstract}
In situ gamma-ray measurements were taken at six locations in the Modane Underground Laboratory. Count rates for gamma radiation within the energy range of $7-2734 \mathrm{keV}$ varied from 15 to $108 \gamma^{-1}$. The arithmetic mean was $79 \gamma^{-1}$ for measurements taken without a collimator. The metamorphic rocks surrounding the Lab are characterized by low activity concentrations of uranium and thorium equal to 12 and $10 \mathrm{~Bq} \mathrm{~kg}^{-1}$, respectively.
\end{abstract}

Keywords Gamma-ray spectrometry · Gamma background · Gamma fluxes · Underground laboratory

\section{Introduction}

The Modane Underground Laboratory (Laboratoire Souterrain de Modane - LSM) is one of the largest underground research centers in Europe. The Laboratory is located in the highway tunnel connecting France and Italy, 1,200 m a.s.l. Including main hall and three secondary halls, the total volume and area of the Lab are $3.52 \times 10^{3} \mathrm{~m}^{3}$ and $4.1 \times 10^{2} \mathrm{~m}^{2}[1,2]$. The scientific programs at LSM comprise particle and astroparticle physics, neutrinoless double beta decay, and ultra-low background experiments [3]. As all these experiments represent investigations of extremely rare events the precise determination of the natural radioactivity background level is required [4, 5].

D. Malczewski ( $\square)$

Faculty of Earth Sciences, University of Silesia, Bedzinska 60,

41-200 Sosnowiec, Poland

e-mail: dariusz.malczewski@us.edu.pl

J. Kisiel · J. Dorda

Institute of Physics, University of Silesia, Uniwersytecka 4,

40-007 Katowice, Poland
After cosmic rays, the most important sources of background radiation are the decays of primordial radionuclides such as ${ }^{40} \mathrm{~K},{ }^{232} \mathrm{Th}$, and ${ }^{238} \mathrm{U}$ in rocks, concrete, and the construction materials used in the detectors. The neutrons originating from $(\alpha, \mathrm{n})$ reactions and the spontaneous fission of $U$ and $T h$ are the main sources of background radiation which can imitate some of the expected signals from the experiments. In this paper we present results of in situ gamma-ray measurements in LSM which were performed in 2006, and laboratory measurements of the parent rock and concrete covering the halls.

\section{Materials and methods}

The background gamma radiation in LSM was measured in situ using a portable gamma-ray spectrometry workstation (Fig. 1). The GX3020 system consisted of a coaxial HPGe detector (32\% efficiency, crystal length $59 \mathrm{~mm}$ and diameter $56.6 \mathrm{~mm}$ ) with a cryostat mounted on a tripod or a special table, a collimator $50 \times 180 \mathrm{~mm}$, a multichannel buffer (InSpector 2000 DSP), and a laptop. The detector bias voltage was $4,000 \mathrm{~V}$ and the energy resolution was $0.8 \mathrm{keV}$ at $122 \mathrm{keV}$ and $1.7 \mathrm{keV}$ at $1.33 \mathrm{MeV}$. For the efficiency calibration and determination of radionuclides the ISOCS (In Situ Object Counting Software), LabSOCS (Laboratory Sourceless Calibration Software) and Genie 2000 v.3 software packages were used. The total duration of a single measurement varied from about 19 to $42 \mathrm{~h}$ (Table 1).

Samples of calcschist (parent rock) and concrete were collected from the main hall, and several months after collection they were measured using the same GX3020 HPGe detector in a lead and copper shield $(60 \mathrm{~mm})$. The spectrometer energy was calibrated using homogeneously 

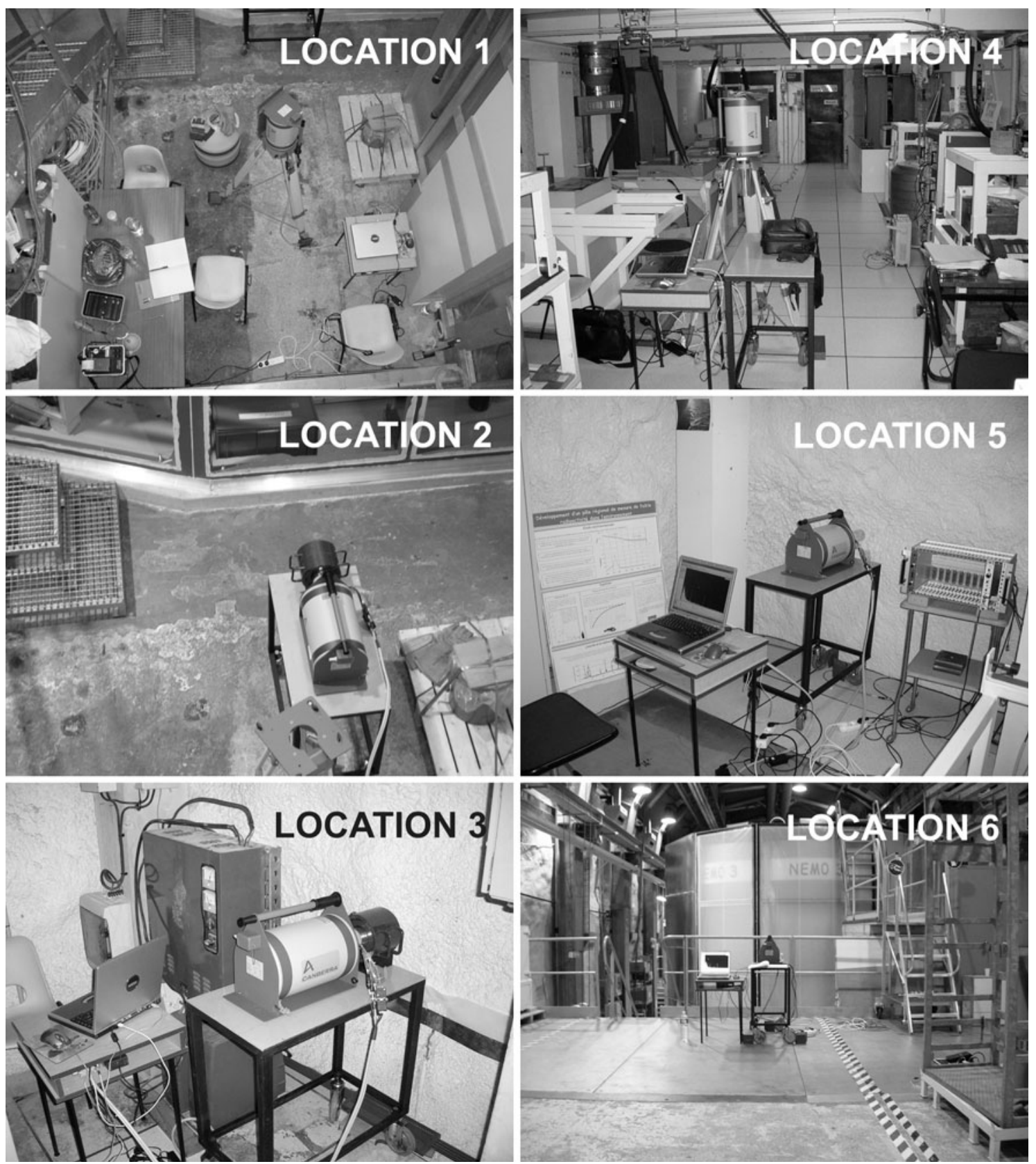

Fig. 1 Location of in situ measurements

dispersed ${ }^{241} \mathrm{Am},{ }^{109} \mathrm{Cd},{ }^{139} \mathrm{Ce},{ }^{57} \mathrm{Co},{ }^{60} \mathrm{Co},{ }^{137} \mathrm{Cs},{ }^{113} \mathrm{Sn}$, ${ }^{85} \mathrm{Sr},{ }^{88} \mathrm{Y}$ and ${ }^{203} \mathrm{Hg}$ radioisotopes in a silicone resin (certificate source type Marinelli Beaker Standard Source [MBSS], supplied by the Czech Metrological Institute). The measurements were done at the Laboratory of Natural Radioactivity (Faculty of Earth Sciences, University of Silesia).

Location of in situ measurements

Measurement location 1 was chosen in front of the NEMO 3 experiment (Fig. 1, location 1). The end cap of the detector was $90 \mathrm{~cm}$ above the concrete base, $3.7 \mathrm{~m}$ away from the NEMO 3 construction and $5.40 \mathrm{~m}$ from the side wall. Location 2 was the same as the first, except the detector with a collimator was mounted horizontally $1 \mathrm{~m}$ from NEMO 3 construction (Fig. 1, location 2). Measurement location 3 was located in the power supply room on the upper level of the Lab. The detector with a collimator was mounted horizontally directly near the wall and $90 \mathrm{~cm}$ above the floor (Fig. 1, location 3). Measurement location 4 was located in the gamma detectors' hall (Fig. 1, location 4). The detector was mounted $90 \mathrm{~cm}$ above the floor, $2.8 \mathrm{~m}$ 
Table 1 Count rates $\left(\gamma \mathrm{s}^{-1}\right)$ in particular energy ranges

\begin{tabular}{lccccccc}
\hline Location & $\begin{array}{l}7.4-2734.2 \\
\mathrm{keV}\end{array}$ & $\begin{array}{l}7.4-249.8 \\
\mathrm{keV}\end{array}$ & $\begin{array}{l}250.2-500.4 \\
\mathrm{keV}\end{array}$ & $\begin{array}{l}500.8-1005.2 \\
\mathrm{keV}\end{array}$ & $\begin{array}{l}1005.6-1555.8 \\
\mathrm{keV}\end{array}$ & $\begin{array}{l}1556.2-2055.8 \\
\mathrm{keV}\end{array}$ & $\begin{array}{l}2056.2-2734.2 \\
\mathrm{keV}\end{array}$ \\
\hline $1(68799)^{\mathrm{a}}$ & $62.24(3)$ & 41.45 & 10.50 & 6.25 & 3.08 & 0.61 & 0.36 \\
$2(85613)$ & $15.12(1)$ & 9.28 & 2.70 & 1.88 & 0.94 & 0.21 & 0.12 \\
$3(84943)$ & $31.25(2)$ & 19.56 & 5.47 & 3.75 & 1.76 & 0.45 & 0.84 \\
$4(86363)$ & $88.37(3)$ & 59.55 & 14.66 & 8.75 & 4.06 & 1.04 & 0.51 \\
$5(85852)$ & $107.86(4)$ & 73.67 & 17.61 & 10.21 & 4.70 & 0.60 & 0.37 \\
$6(151252)$ & $57.07(2)$ & 36.81 & 10.48 & 6.10 & 2.72 & & 0.61 \\
\hline
\end{tabular}

Measurements at location 2 and 3 were performed using a collimator

a Measurement time $(s)$

from the side walls and $9 \mathrm{~m}$ away from the entrance to the hall. Location 5 was the same as 4 , except the detector was mounted horizontally directly near the wall and $90 \mathrm{~cm}$ above the floor (Fig. 1, location 5). The last measuring point (location 6) was on a metal platform in front of the NEMO 3 experiment. The detector was mounted horizontally $90 \mathrm{~cm}$ above the platform and $5 \mathrm{~m}$ away from the NEMO 3 construction (Fig. 1, location 6). The gamma-ray spectra from all locations are presented in Fig. 2.

\section{Results and discussion}

The count rates $\left(\gamma s^{-1}\right)$ at all measurement locations are listed in Table 1, and the gamma fluxes in $\gamma \mathrm{cm}^{-2} \mathrm{~s}^{-1}$ from locations 2 and 3 are given in Table 2 . The count rates in the main gamma peaks and the gamma fluxes from these peaks at locations 2 and 3 are presented in Tables 3 and 4, respectively. Table 5 summarizes the results of the activity measurements in the parent rock and in concrete from the main hall.

In situ measurements

The total count rates between energy range of 7.4-2734.2 keV varied from 15 at location 2 to $\sim 108 \gamma^{-1}$ at location 5 (Table 1). The arithmetic mean for measurements without a collimator (locations 1, 4, 5 and 6) was 79(23) $\gamma \mathrm{s}^{-1}$ (Fig. 3a). As expected the highest count rates were noted between 7.4 and $249.8 \mathrm{keV}$ with an average contribution of 0.65 for all measurement locations (Fig. 3b). The count rates at subsequent energy ranges noticeably decreased, with average contributions of 0.17 , $0.11,0.05,1.1 \times 10^{-2}$, and $7 \times 10^{-3}$ within ranges 250-500, 501-1005, 1,006-1,556, 1,556-2,056, and 2,056-2,734 keV, respectively (Fig. 3b). The lowest count rates (both with and without a collimator) at locations 2 and 6 indicate that the metal elements inside the Lab show the smallest contribution to the total background.

For measurements using a collimator (locations 2 and 3) the highest total gamma flux, $0.622 \mathrm{\gamma} \mathrm{cm}^{-2} \mathrm{~s}^{-1}$, was noted at location 3. At location 2 the total gamma flux, $0.301 \gamma \mathrm{cm}^{-2} \mathrm{~s}^{-1}$, was two times lower than at location 3 (Table 2). Similar to the count rates, the particular contributions of these gamma fluxes rapidly decrease with increasing energy; they are on the order of $10^{-2}$ in the range $250-1,556 \mathrm{keV}$, and $10^{-3}$ in the range 1556-2734 keV. The highest integral areas from the main gamma transitions (except point 2) were noted under the peak at $351.9 \mathrm{keV}\left({ }^{214} \mathrm{~Pb}\right)$ and then under the peaks at $609.3\left({ }^{214} \mathrm{Bi}\right)$ and $1460.8 \mathrm{keV}\left({ }^{40} \mathrm{~K}\right)$ (Table 3). The two most intense gamma transitions from thorium series i.e., $911.6 \mathrm{keV}\left({ }^{228} \mathrm{Ac}\right)$ and $2614.5 \mathrm{keV}\left({ }^{208} \mathrm{Tl}\right)$ are characterized by reduced areas compared with lines of 351.9, 609.3 and $1460.8 \mathrm{keV}$. The gamma transition of $2204.2 \mathrm{keV}$ from ${ }^{214} \mathrm{Bi}$ is characterized by the lowest count rates ranging from $0.03 \gamma^{-1}$ at location 6 to $0.06 \gamma \mathrm{s}^{-1}$ at location 5 (measurements without a collimator). Despite the low yield (1.28\%) of the $2,204.2 \mathrm{keV}$ transition [6], its contribution may be important to geo-neutrino experiments because its possible overlap with the deuteron binding energy of $2.2 \mathrm{MeV}$ [7]. This energy is released as gamma rays as a result of inverse beta-decay in a liquid scintillator.

Gamma fluxes at locations 2 and 3 (measurements with a collimator) are on the order of $10^{-3} \gamma \mathrm{cm}^{-2} \mathrm{~s}^{-1}$ for the peaks at $351.9,609.3$ and $1460.8 \mathrm{keV}$, and on the order of $10^{-4} \gamma \mathrm{cm}^{-2} \mathrm{~s}^{-1}$ for the peaks at 911.6, 2204.2 and $2614.5 \mathrm{keV}$ (Table 4).

The gamma rays emitted from calibration sources as ${ }^{137} \mathrm{Cs}$ (peak $661.6 \mathrm{keV}$ ) and ${ }^{60} \mathrm{Co}$ (peaks $1,173.2$ and $1,332.5 \mathrm{keV}$ ) [8] are visible in the spectra at locations 1,4 , 5 and 6 . The count rates in these peaks varied from 0.071 (location 6) to $0.088 \gamma \mathrm{s}^{-1}$ (locations 1 and 5), and 0.064 (location 6) to $0.305 \mathrm{\gamma} \mathrm{s}^{-1}$ (location 4) for ${ }^{137} \mathrm{Cs}$ and ${ }^{60} \mathrm{Co}$, respectively. The values for ${ }^{60} \mathrm{Co}$ are given as the sum of peaks 1173.2 and $1332.5 \mathrm{keV}$.

Laboratory measurements

The results of the activity measurements for calcschist (Fig. 4) and concrete collected from the main hall are given 

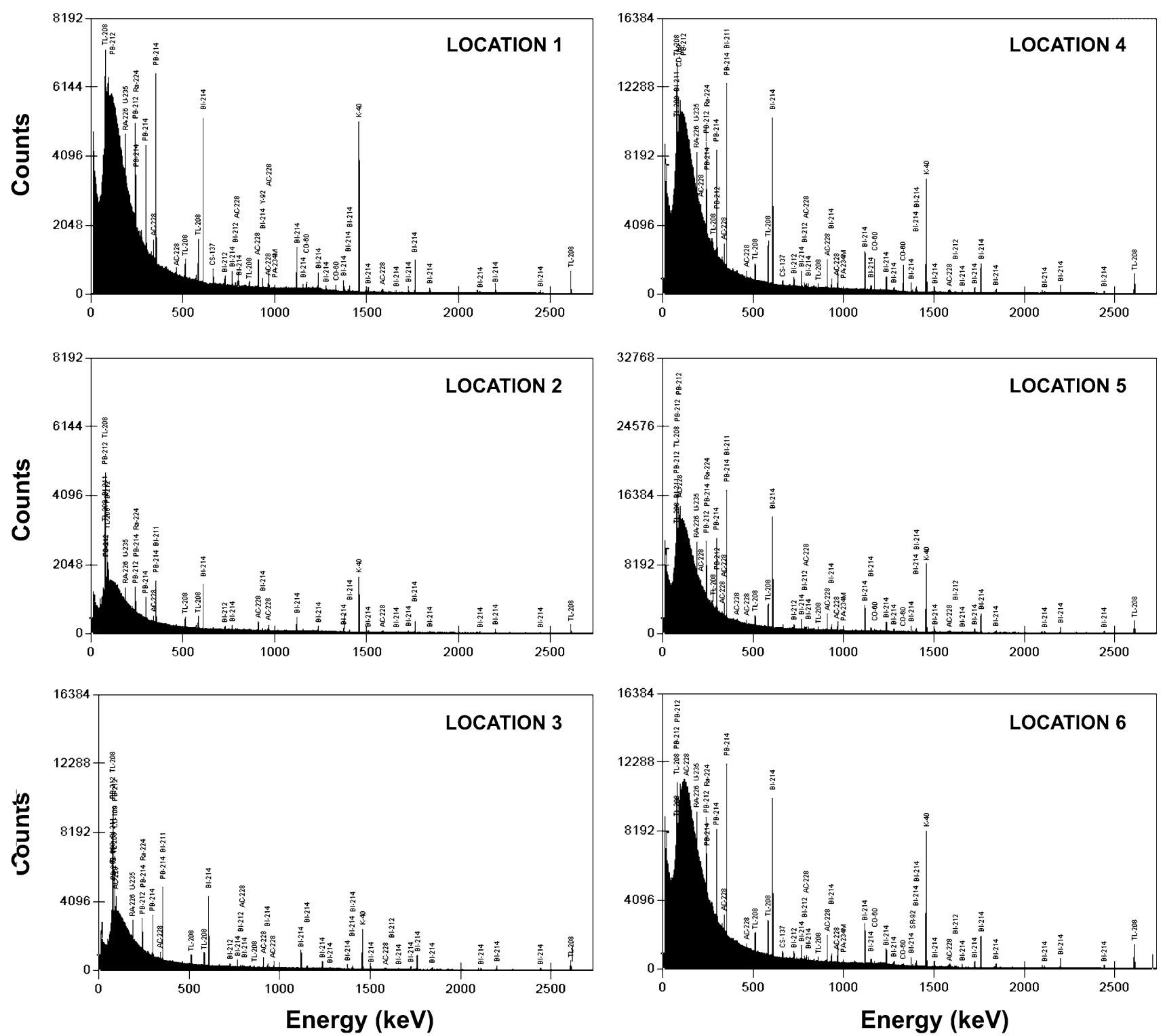

Fig. 2 In situ gamma-ray spectra at specified locations. The characteristic gamma-ray emitters are marked above the corresponding peaks

Table 2 Gamma fluxes in $\gamma \mathrm{cm}^{-2} \mathrm{~s}^{-1}$ in specified energy ranges at location 2 and 3

\begin{tabular}{llllllll}
\hline Location & $\begin{array}{l}7.4-2734.2 \\
\mathrm{keV}\end{array}$ & $\begin{array}{l}7.4-249.8 \\
\mathrm{keV}\end{array}$ & $\begin{array}{l}250.2-500.4 \\
\mathrm{keV}\end{array}$ & $\begin{array}{l}500.8-1005.2 \\
\mathrm{keV}\end{array}$ & $\begin{array}{l}1005.6-1555.8 \\
\mathrm{keV}\end{array}$ & $\begin{array}{l}1556.2-2055.8 \\
\mathrm{keV}\end{array}$ & $\begin{array}{l}2056.2-2734.2 \\
\mathrm{keV}\end{array}$ \\
\hline 2 & 0.301 & 0.185 & $5.36 \times 10^{-2}$ & $3.74 \times 10^{-2}$ & $1.87 \times 10^{-2}$ & $4.10 \times 10^{-3}$ & $2.40 \times 10^{-3}$ \\
3 & 0.622 & 0.389 & 0.109 & $7.47 \times 10^{-2}$ & $3.51 \times 10^{-2}$ & $8.89 \times 10^{-3}$ & $5.01 \times 10^{-3}$ \\
\hline
\end{tabular}

in Table 5. As seen the table, the activity concentration in $\mathrm{Bq} \mathrm{kg}^{-1}$ and the concentration in $10^{-6} \mathrm{gg}^{-1}$ of ${ }^{238} \mathrm{U}$ is two times higher in concrete than in calcschist, whereas ${ }^{40} \mathrm{~K}$ concentrations in $\mathrm{Bq} \mathrm{kg}^{-1}$ and $10^{-6} \mathrm{gg}^{-1}$ in calcschist is two times higher than in concrete. The activity concentrations of ${ }^{232} \mathrm{Th}$ are comparable (Table 5). Activity concentrations of ${ }^{40} \mathrm{~K},{ }^{232} \mathrm{Th}$ and ${ }^{238} \mathrm{U}$ equal to $213(30), 10.1(8)$ and
10.4(25) $\mathrm{Bq} \mathrm{kg}^{-1}$, respectively, have been reported in calcschist, and concentrations equal to $77(13), 5.8(8)$ and 23.5(25), respectively, have been noted in concrete in LSM by Chazal et al. (1998) [9]. These values are consistent with the results obtained in our measurements. Generally, the concrete covering walls in LSM shows activity concentrations of ${ }^{40} \mathrm{~K},{ }^{232} \mathrm{Th}$ and ${ }^{238} \mathrm{U}$ comparable with 
Table 3 Count rates $\left(\gamma \mathrm{s}^{-1}\right)$ in the main gamma peaks

\begin{tabular}{|c|c|c|c|c|c|c|}
\hline Location & $\begin{array}{l}351.9 \mathrm{keV} \\
{ }^{214} \mathrm{~Pb}\left({ }^{238} \mathrm{U}\right) \\
1.22 \mathrm{keV}^{\mathrm{a}}\end{array}$ & $\begin{array}{l}609.3 \mathrm{keV} \\
{ }^{214} \mathrm{Bi}\left({ }^{238} \mathrm{U}\right) \\
1.41 \mathrm{keV}\end{array}$ & $\begin{array}{l}911.6 \mathrm{keV} \\
{ }^{228} \mathrm{Ac}\left({ }^{232} \mathrm{Th}\right) \\
1.56 \mathrm{keV}\end{array}$ & $\begin{array}{l}1460.8 \mathrm{keV} \\
{ }^{40} \mathrm{~K} \\
1.87 \mathrm{keV}\end{array}$ & $\begin{array}{l}2204.2 \mathrm{keV} \\
{ }^{214} \mathrm{Bi}\left({ }^{238} \mathrm{U}\right) \\
2.17 \mathrm{keV}\end{array}$ & $\begin{array}{l}2614.5 \mathrm{keV} \\
{ }^{208} \mathrm{Tl}\left({ }^{232} \mathrm{Th}\right) \\
2.44 \mathrm{keV}\end{array}$ \\
\hline 1 & $0.496^{\mathrm{b}}$ & 0.402 & 0.105 & 0.456 & 0.032 & 0.074 \\
\hline 2 & 0.106 & 0.090 & 0.031 & 0.120 & 0.010 & 0.024 \\
\hline 3 & 0.303 & 0.264 & 0.066 & 0.179 & 0.023 & 0.050 \\
\hline 4 & 0.731 & 0.601 & 0.150 & 0.466 & 0.045 & 0.103 \\
\hline 5 & 1.014 & 0.812 & 0.184 & 0.600 & 0.058 & 0.125 \\
\hline 6 & 0.448 & 0.361 & 0.097 & 0.332 & 0.030 & 0.075 \\
\hline
\end{tabular}

Measurements at locations 2 and 3 were performed using a collimator

${ }^{a}$ Full width at half maximum (FWHM)

b Estimated uncertainty of peak areas $\leq 5 \%$

Table 4 Gamma fluxes in $\gamma \mathrm{cm}^{-2} \mathrm{~s}^{-1}$ from the main gamma peaks, at locations 2 and 3

\begin{tabular}{|c|c|c|c|c|c|c|}
\hline Location & $\begin{array}{l}351.9 \mathrm{keV} \\
{ }^{214} \mathrm{~Pb}\left({ }^{238} \mathrm{U}\right) \\
1.22 \mathrm{keV}^{\mathrm{a}}\end{array}$ & $\begin{array}{l}609.3 \mathrm{keV} \\
{ }^{214} \mathrm{Bi}\left({ }^{238} \mathrm{U}\right) \\
1.41 \mathrm{keV}\end{array}$ & $\begin{array}{l}911.6 \mathrm{keV} \\
{ }^{228} \mathrm{Ac}\left({ }^{232} \mathrm{Th}\right) \\
1.56 \mathrm{keV}\end{array}$ & $\begin{array}{l}1460.8 \mathrm{keV} \\
{ }^{40} \mathrm{~K} \\
1.87 \mathrm{keV}\end{array}$ & $\begin{array}{l}2204.2 \mathrm{keV} \\
{ }^{214} \mathrm{Bi}\left({ }^{238} \mathrm{U}\right) \\
2.17 \mathrm{keV}\end{array}$ & $\begin{array}{l}2614.5 \mathrm{keV} \\
{ }^{208} \mathrm{Tl}\left({ }^{232} \mathrm{Th}\right) \\
2.44 \mathrm{keV}\end{array}$ \\
\hline 2 & $2.10 \times 10^{-3}$ & $1.78 \times 10^{-3}$ & $6.10 \times 10^{-4}$ & $2.40 \times 10^{-3}$ & $2.02 \times 10^{-4}$ & $4.78 \times 10^{-4}$ \\
\hline 3 & $6.04 \times 10^{-3}$ & $5.26 \times 10^{-3}$ & $1.31 \times 10^{-3}$ & $3.55 \times 10^{-3}$ & $4.53 \times 10^{-4}$ & $1.00 \times 10^{-3}$ \\
\hline
\end{tabular}

${ }^{a}$ Full width at half maximum (FWHM)

${ }^{\mathrm{b}}$ Estimated uncertainty of peak areas $\leq 5 \%$

Table 5 Calcschist and concrete ${ }^{40} \mathrm{~K},{ }^{232} \mathrm{Th}$ and ${ }^{238} \mathrm{U}$ concentrations

Calcschist (parent rock)

${ }^{40} \mathrm{~K}\left(\mathrm{Bqkg}^{-1}\right)$

182(4)

$\mathrm{K}\left(10^{-6} \mathrm{gg}^{-1}\right)$

0.71(1)

Concrete

\begin{tabular}{|c|c|c|}
\hline${ }^{40} \mathrm{~K}\left(\mathrm{~Bq} \mathrm{~kg}^{-1}\right)$ & ${ }^{232} \mathrm{Th}\left(\mathrm{Bq} \mathrm{kg}^{-1}\right)$ & ${ }^{238} \mathrm{U}\left(\mathrm{Bq} \mathrm{kg}{ }^{-1}\right)$ \\
\hline $91(3)$ & $6.7(2)$ & $22.8(7)$ \\
\hline $\mathrm{K}\left(10^{-6} \mathrm{gg}^{-1}\right)$ & ${ }^{232} \operatorname{Th}\left(10^{-6} \mathrm{gg}^{-1}\right)$ & ${ }^{238} \mathrm{U}\left(10^{-6} \mathrm{gg}^{-1}\right)$ \\
\hline $0.36(1)$ & $1.63(5)$ & $1.83(3)$ \\
\hline
\end{tabular}

concentrations observed for typical limestone concretes i.e., $89,8.5$ and $31 \mathrm{~Bq} \mathrm{~kg}^{-1}$, respectively [10]. The activity concentrations of ${ }^{40} \mathrm{~K},{ }^{232} \mathrm{Th}$ and ${ }^{238} \mathrm{U}$ directly calculated during in situ measurement (location 3) were 19.7(7), 6.2(2) and $80(1) \mathrm{Bq} \mathrm{kg}^{-1}$, respectively. These results indicate that the most important sources of gamma background inside the Lab are decays of primordial radionuclides in limestone concrete that covers the parent rock.

\section{Conclusions}

The gamma background inside the Laboratoire Souterrain de Modane is low and characterized by count rates at the
Fig. 3 a Count rates at all locations. Thick solid line - an average count rate from measurements without a collimator (79). b Average contributions of count rates within the particular energy ranges from all locations
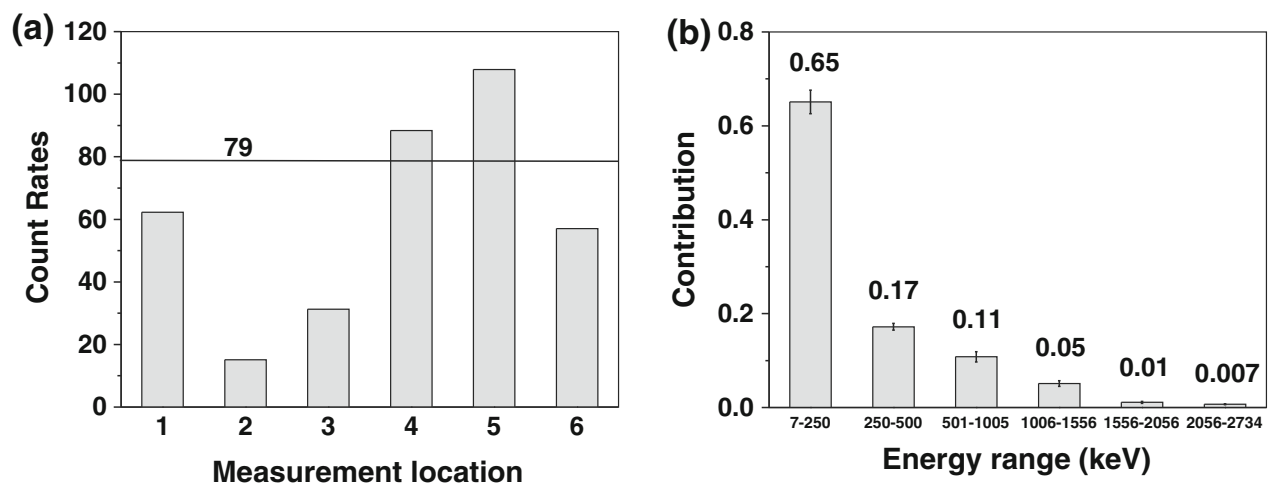

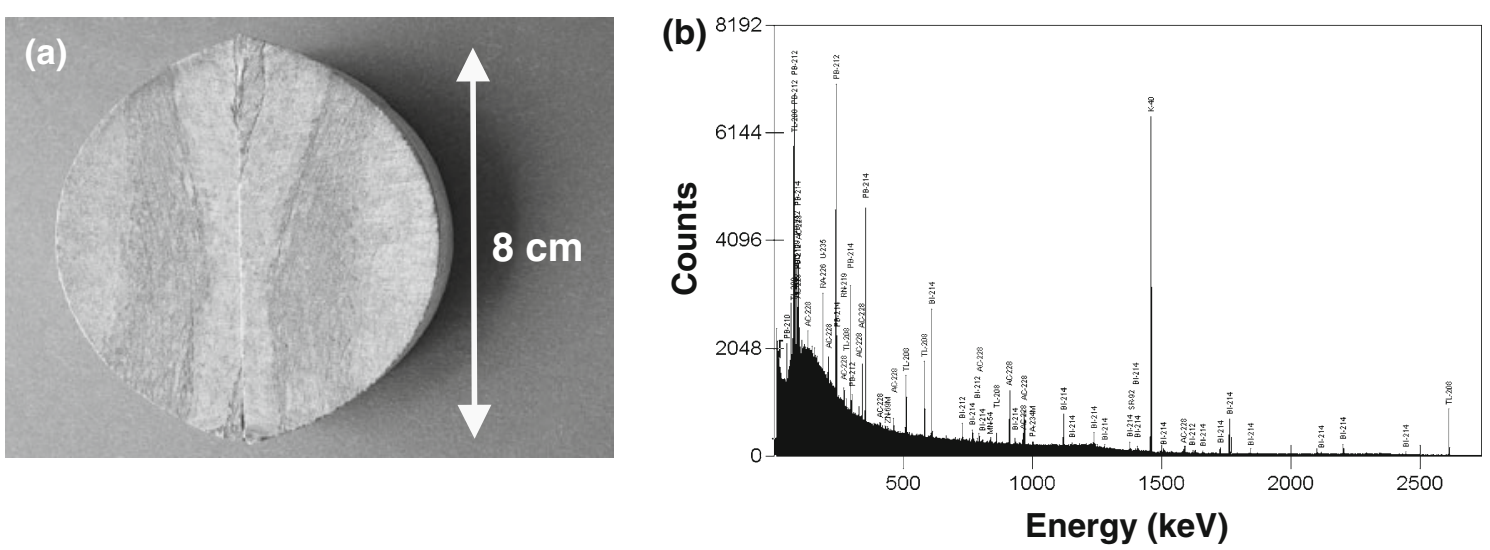

Fig. 4 a A photograph of calcschist sample used in this study. b Corresponding gamma-ray spectrum; the characteristic gamma-ray emitters are marked above the corresponding peaks

level of $79 \mathrm{\gamma s}^{-1}$ in the energy range of $7-2734 \mathrm{keV}$. Gamma fluxes obtained from two locations were 0.301 and $0.622 \gamma \mathrm{cm}^{-2} \mathrm{~s}^{-1}$. The construction materials inside the Lab do not contribute significantly to the total gamma background.

Acknowledgment This publication was supported by EU funds under the contract ILIAS RII3-CT-2004-506222.

Open Access This article is distributed under the terms of the Creative Commons Attribution Noncommercial License which permits any noncommercial use, distribution, and reproduction in any medium, provided the original author(s) and source are credited.

\section{References}

1. Miramonti L (2005) European underground laboratories: an overview. arXiv:hep-ex/0503054v1

2. Loaiza P (2005) Low radioactivity at the Modane underground laboratory in topical workshop on low radioactivity techniques, edited by Cleveland B, Ford R, and Chen M (American Institute of Physics), pp 100-103
3. Aalseth C, Andreotti E, Dirk Arnold D, Sanchez Cabeza JA, Degering D, Giuliani A, Gonzales de Orduna R, Gurriaran R, Mikael Hult M, Keillor M, Laubenstein M, Le Petit G, Margineanu RM, Matthews M, Miley H, Osvath I, Pellicciari M, Plastino W, Simgen H, Weber M, Werzi R (2009) Ultra-low background measurements of decayed aerosol filters. J Radioanal Nucl Chem 282:731-735

4. Miramonti L (2002) A very low background HPGe detector operating deep underground at 4,800 m water equivalent. Appl Radiat Isot 57:209-212

5. Niese S, Koehler M, Gleisberg B (1998) Low-level counting techniques in the underground laboratory Felsenkeller in Dresden. J Radioanal Nucl Chem 233:167-172

6. Firestone RB (1996) Table of isotopes. Wiley-Interscience, Lawrence Berkeley National Laboratory, Berkeley

7. Dye ST (ed) (2006) Neutrino geophysics. Springer, Dordrecht

8. Debertin K, Helmer RG (1988) Gamma-and X-Ray spectrometry with semiconductor detectors. Elsevier Science Publishers, Amsterdam

9. Chazal V, Brissot R, Cavaignac JF, Chambon B, De Jesus M, Drain D, Giraud-Heraud Y, Pastor C, Stutz A, Vagneron L (1998) Neutron background measurements in the underground laboratory of Modane. Astrop Phys 9:163-172

10. Eisenbud M, Gesell T (1997) Environmental radioactivity from natural, industrial, and military sources. Academic Press, San Diego, pp 134-200 